\title{
In situ swimming and feeding behavior of eight co-occurring hydromedusae
}

\author{
Sean P. Colin ${ }^{1, *}$, John H. Costello ${ }^{2}$, Eric Klos ${ }^{3}$ \\ ${ }^{1}$ Department of Biology, Roger Williams University, 1 Old Ferry Road, Bristol, Rhode Island 02809, USA \\ ${ }^{2}$ Department of Biology, Providence College, Providence, Rhode Island 02918, USA \\ ${ }^{3}$ Graduate School of Oceanography, The University of Rhode Island, South Ferry Road, Narragansett, Rhode Island 02882, USA
}

\begin{abstract}
The morphology, swimming kinematics and prey selection of hydromedusae have been shown to be closely related to hydromedusan foraging mode. In order to confirm this link, we examined the in situ foraging behavior of hydromedusae by video-recording and quantifying the in situ swimming activity and tentacle-extension behavior of 8 co-occurring hydromedusae from the waters surrounding Friday Harbor, Washington. The cruising-predatory medusae Aequorea victoria, Mitrocoma cellularia, Phialidium gregarium, and Eutonina indicans spent a greater proportion of their time swimming (on average from 74.1 to $92.1 \%$ ) than the ambush-predatory medusae Aglantha digitale, Sarsia sp., Leuckartiara sp., and Stomotoca atra (on average from 19.5 to $47.0 \%$ ). In addition, the cruising-predatory medusae were observed with their tentacles extended almost continuously, regardless of whether they were swimming or drifting. In contrast, the ambush-predatory medusae drifted with their tentacles extended but contracted their tentacles when swimming. These patterns indicate that cruising-predatory medusae can feed while either swimming or drifting, whereas the ambush-predatory medusae feed while drifting but not while swimming. Thus, swimming plays a distinctly different role within the behavioral repertoire of each of these medusan foraging modes. Furthermore, the swimming activity and tentacle-extension behavior we observed were consistent with strategies that optimized feeding by each of the predator types.
\end{abstract}

KEY WORDS: Jellyfish $\cdot$ Foraging $\cdot$ Time budgets $\cdot$ Ambush predation $\cdot$ Cruising predation

Resale or republication not permitted without written consent of the publisher

Hydromedusae have been found to substantially affect zooplankton prey populations, and are often dominant predators in coastal ecosystems (Larson 1987, Purcell \& Grover 1990, Matsakis \& Conover 1991). Understanding determinates of the foraging behavior of hydromedusa can provide insight into factors determining their trophic impact. The modes of propulsion, bell morphology and prey selection vary among hydrozoan taxa and are thought to be directly linked to the foraging behavior of hydromedusae (Colin \& Costello 2002, Costello \& Colin 2002). Accordingly, Costello \& Colin (1995) have suggested that propulsion and bell morphology can be used to predict the impact that different hydromedusae have upon zooplankton prey populations.

Laboratory observations have shown that some medusae, including hydromedusae and scyphomedusae, use the flow produced during swimming to draw prey into their tentacles. For these medusae, swimming and prey capture are simultaneous, interrelated events (Costello 1992, Costello \& Colin 1994, Ford et al. 1997). Colin \& Costello (2002) have suggested that these medusae generally have oblate bell morphologies (fineness ratio generally $<0.5$ ) and have termed them 'rowers' because, as they contract their bells during swimming, their bell margin acts as a paddle and propels them forward. Both the oblate bell shape and the rowing propulsive mode are favorable for these medusae because these traits maximize the flow generated during swimming, i.e. the feeding current, and appear to decrease the energy expended during swimming (Colin \& Costello 1996, 2002).

Other hydromedusae forage by drifting with their tentacles extended (Madin 1988). In these medusae, it is suspected that swimming is decoupled from feeding. These taxa use jet propulsion to swim and, thus, are termed 'jetters' (Colin \& Costello 2002). Jet propulsion enables ambush predators to reposition themselves more quickly but appears to be a more energetically expensive mode of propulsion (Colin \& Costello 1996, 2002). The more prolate bells of these medusae (fineness ratio generally $>0.5$ ) decrease their drag and bell contraction times making them highly proficient swimmers (Daniel 1983). 
In situ prey-selection data indicate that the different mechanisms of prey capture used by rowers versus jetters result in dietary differences and, therefore, different trophic roles (Costello \& Colin 2002). We would predict, based upon the morphology, swimming performance and prey selection of the different medusan groups, that in order to optimize foraging success and trophic impact, rowing medusae should maximize and jetting medusae should minimize their time spent swimming.

The goal of this study was to determine whether the in situ foraging behavior of hydromedusae is consistent with these predictions. Specifically, we examined the in situ swimming activity, defined as the proportion of time allocated to swimming, of 8 hydromedusan species (Aequorea victoria, Mitrocoma cellularia, Phialidium gregarium, Eutonina indicans, Aglantha digitale, Sarsia sp., Leuckartiara sp., Stomotoca atra; Fig. 1) co-occurring in the waters surrounding Friday Harbor, Washington, USA. We then related swimming activity to feeding activity; where feeding medusae were defined as medusae with their tentacles extended.
Materials and methods. Based on morphology, propulsive mode and feeding mode, Aequorea, Mitrocoma, and Phialidium have been previously categorized as rowers and Aglantha and Sarsia as jetters (Colin \& Costello 2002, Costello \& Colin 2002). Based on their morphologies, we categorized the oblate Eutonina as a rower and the prolate Leuckartiara and Stomotoca as jetters.

In situ data were collected from shallow water sites, $<10$ m depth, in Friday Harbor, Washington, USA, by SCUBA divers in natural daylight. Data collection followed the methods of Costello et al. (1998). Accordingly, medusae were videotaped on Hi8 videotape using a Sony TR81 camera with a zoom lens contained within an Amphibico underwater housing. Camera orientation paralleled the sediment and water surface.

To avoid disturbing the medusae, video observations were made using natural lighting and by divers and cameras maintaining a fixed position, while medusae were carried toward the divers by ambient currents. This allowed the medusae to drift past the camera and minimized disturbance. Thus, lighting and mechanical disturbance were negligible factors influencing medu-
A.

Aglantha digitale
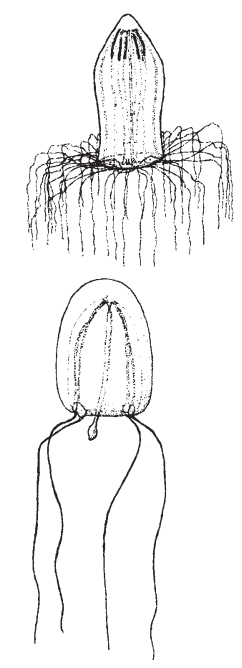

Sarsia sp.
B.

Eutonina indicans

Stomotoca atra
Leuckartiara sp.
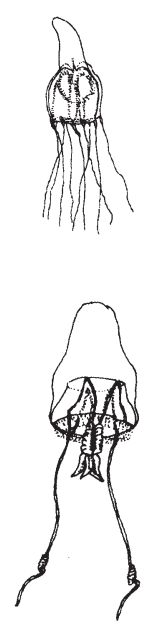

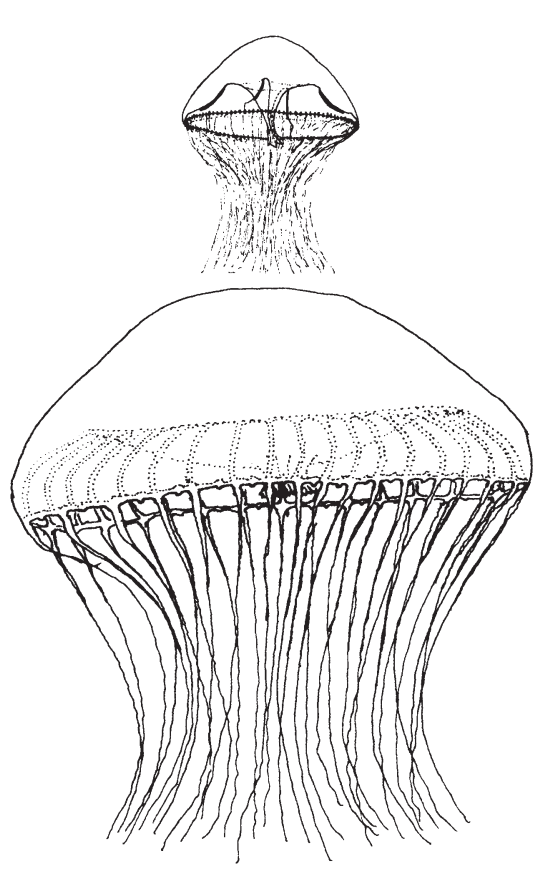

Aequorea victoria

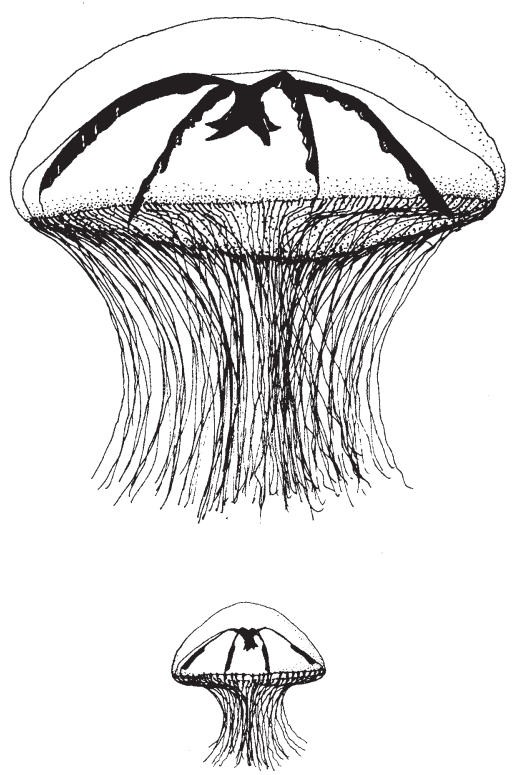

Phialidium

gregarium

$1 \mathrm{~cm}$

Fig. 1. Eight co-occurring hydromedusae of the Puget Sound, Washington, USA, depicted in their feeding modes. The jetters (A) Aglantha digitale, Leuckartiara sp., Sarsia sp. and Stomotoca atra are sitting motionlessly with their tentacles extended. The rowers (B) Eutonina indicans, Mitrocoma cellularia, Aequorea victoria and Phialidium gregarium are swimming with their tentacles extended. Notice the different scales for the jetters versus rowers 
san behavior. However, this method led to short observations of each medusa (mean $=22.9 \mathrm{~s}$ per observation). To compensate for brief individual observations, and to increase the overall observation times, we sampled a large number of medusae of each species.

Medusan behavior was divided into 2 categories: swimming (presence of active bell pulsation) and resting (absence of bell pulsation). The total time each medusa spent swimming or drifting was measured by summing the number of frames (each $1 / 30 \mathrm{~s}$ ) over which the behavior was observed using time-code-labeled videotapes (Costello et al. 1998). We designated the medusae as feeding when at least some of their tentacles were extended. They were designated as nonfeeding if all of their tentacles were retracted. This assumption is based upon the premise that hydromedusae feed primarily by capturing prey on their tentacles and therefore at least some tentacle extension is required for feeding activity. For some medusae, bell contraction at the onset of a swimming bout caused all of the tentacles of the medusae to contract. In such cases, we identified these as feeding medusae before the onset of swimming, i.e. when at rest, and nonfeeding medusae after the onset of swimming.

Results. An examination of the percent times spent swimming by both the rowing and jetting hydromedusae revealed that the median values were more indicative of the central tendency of the data than the means of the percent times spent swimming because the majority of the medusae were observed swimming either 100 (for rowers) or $0 \%$ (for jetters) of the time. However, a small number of individuals of all species swam for periods other than 0 or $100 \%$, resulting in high standard deviations from the mean percentage of the time spent swimming. As a consequence of the highly skewed swimming frequencies (Fig. 2), we used the non-parametric Kruskal-Wallis median test to compare the percent of time that rowers spent swimming to that of the jetters (Siegel \& Castellan 1988, Costello et al. 1998).

It is evident from the percent times spent swimming that all of the medusae we categorized as rowing species, Aequorea $(\mathrm{n}=126)$, Mitrocoma $(\mathrm{n}=157)$, Phialidium ( $\mathrm{n}=113$ ) and Eutonina $(\mathrm{n}=55)$, swam nearly continuously (all medians $=100 \%$, means $\geq 74.1 \%$; Fig. 2). In contrast, most of the jetting species were rarely observed swimming (Aglantha, n = 49; Sarsia, n = 120; Leuckartiara, $\mathrm{n}=12$; Fig. 2). As a result, the rowers spent significantly more time swimming than the jetting hydromedusae (Kruskal-Wallis median test, $\mathrm{p}<0.0001)$.

Likewise, we observed differences between the 2 groups in how swimming activity related to tentacle extension. Most of the rowing medusae were observed with tentacles extended both when swimming and drifting (Fig. 3). Consequently, the comparison of the

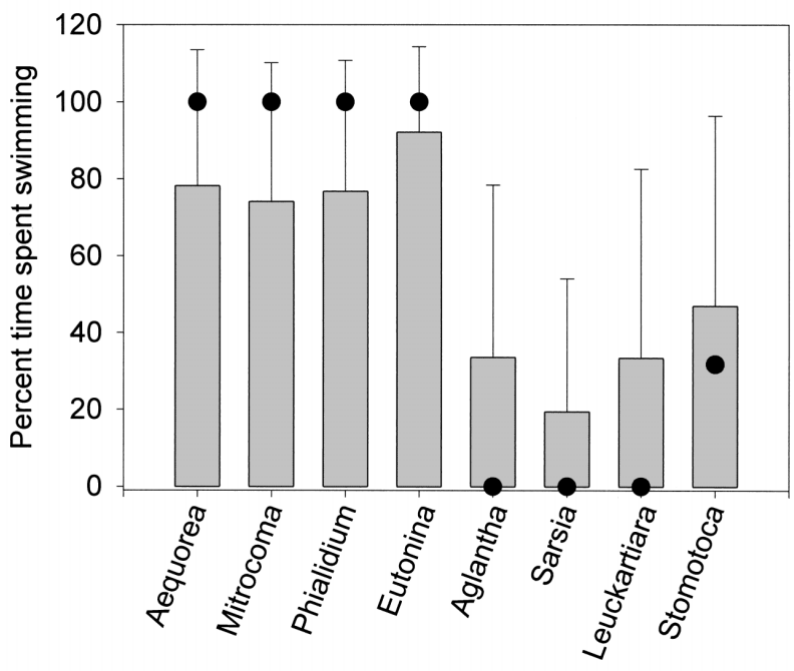

Fig. 2. Mean (bars + SD) and median (๑) percent of the time each hydromedusan species was observed swimming

percentages of medusae observed swimming versus drifting with their tentacles extended revealed that these percentages did not differ for any of the rowing species $\left(\chi^{2}, p>0.15\right.$ for all of the rowing species). The jetting species, in contrast, contracted their tentacles more often while swimming than drifting $\left(\chi^{2} ; \mathrm{p}<0.005\right.$ for all of the jetting species; Fig. 3). In fact, almost none of the jetters were observed swimming with their tentacles extended. Thus, the main distinction between foraging modes was that jetting medusae retracted their tentacles while swimming.

Stomotoca $(\mathrm{n}=12$ ) was the only jetting species that did not spend a substantial majority of its time drifting, and the only one with a median percentage of time swimming greater than zero (Fig. 2). Like the other jetting hydromedusae, it contracted its tentacles when it initiated swimming activity, indicating it does not feed while swimming (Fig. 3). Therefore, it most likely uses swimming to regularly reposition itself while foraging in a sink-and-swim pattern (Mills 1983).

Discussion. These in situ observations demonstrate that the propulsive modes of the medusae studied are related to the amount of time they spend swimming. Clearly, the rowing medusae are foraging as cruising predators while the jetters are foraging as ambush predators. The observations of the few studies that have empirically examined or anecdotally mentioned swimming activity of hydromedusae were generally consistent with our findings. Rowing species swim the majority of the time (Mackie et al. 1981, Mills 1983, Madin 1988), while jetting species drift the majority of the time (Leonard 1980, Mills 1983, Arkett 1984, Larson 1987, Madin 1988). However, in situ swimming activity has not been studied in conjunction with feeding behavior. If we consider the patterns observed in 

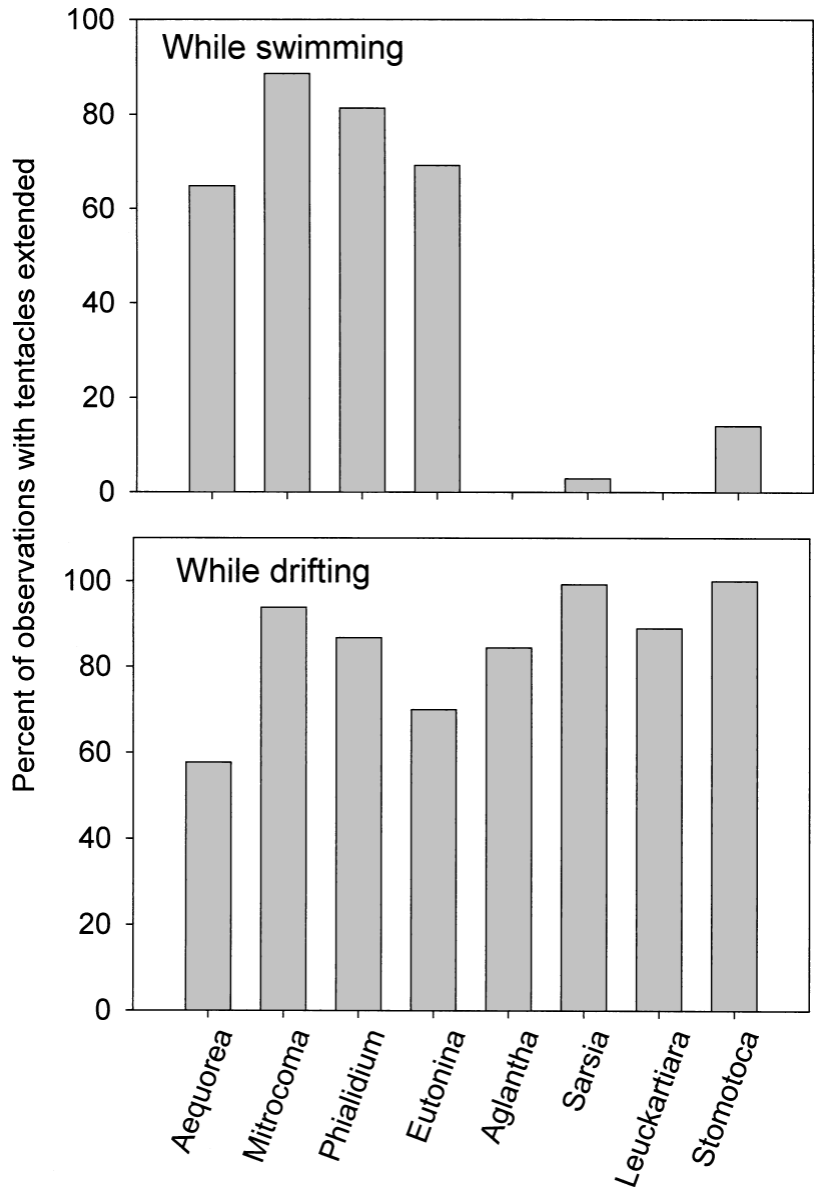

Fig. 3. Percent of medusae observed swimming (upper panel) and drifting (lower panel) with their tentacles extended

this study in terms of the foraging mode of the medusae, it becomes clear that members of each propulsive mode coordinated swimming and tentacle extension behavior in ways which optimized feeding activity. For rowing medusae, including Aequorea, Mitrocoma, Phialidium and Eutonina, the flow created during swimming draws prey to their tentacles (Costello \& Colin 1995). Thus, by swimming almost continuously with their tentacles extended, these medusae are foraging as cruising predators and maximizing their time spent foraging. In contrast, the jetters, including Aglantha, Sarsia, Leuckartiara and Stomotoca, feed while motionlessly drifting and capturing prey that swim into their extended tentacles. By spending most of their time drifting with their tentacles extended, these medusae are foraging as ambush medusae and maximizing their time spent foraging.

As Fig. 3 illustrates, ambush medusae did not swim with their tentacles extended, indicating that they did not feed while swimming. Swimming for these jetting medusae would be used for repositioning and escaping from predators and might be expected to optimize swimming performance (e.g. velocity and acceleration) in order to minimize the amount of time between feeding bouts. It has been shown that prolate bell morphologies (Fig. 1), rapid bell-contraction times and the propulsive mode of ambush medusae are traits that optimize swimming performance (Gladfelter 1973, Daniel 1983, 1985, Colin \& Costello 2002). Tentacle contraction during swimming can be considered adaptation that further increases the swimming performance of jetting medusae. By contracting their tentacles during swimming, these hydromedusae reduce the drag associated with trailing tentacles.

In contrast to jetting medusae, there is no clear advantage for rowing medusae to contract their tentacles while drifting. Perhaps for this reason, we observed no differences in the tentacle-extension behavior between swimming and drifting medusae (Fig. 3). This indicates that rowing medusae may feed as both cruising predators while swimming and ambush predators while drifting. It should be pointed out, however, that since we observed almost continuous swimming activity by the rowing species, cruising appears to be their dominant foraging mode.

These in situ observations of the swimming activity and tentacle-extension behavior of hydromedusae have confirmed what laboratory observations of hydromedusan morphology, kinematics and propulsive mode have suggested. These observations indicate that the different roles of swimming for the ambush and cruising predators result in differences in what may be considered as optimal swimming within the groups. Optimal swimming for cruising medusae is that which generates the greatest amount of flow and enables them to swim with a low energy expense for long periods of time. For ambush medusae, optimal swimming maximizes their velocity and acceleration while minimizing the time required to change position. These traits, in combination with others such as nematocyst complements (Purcell \& Mills 1988) and tentacle deployment (Mills 1981, Madin 1988), are the elements underlying trophic impacts and dietary niches of hydromedusae (Costello \& Colin 2002).

Acknowledgements. Funding for this project was provided by NSF grants OCE-9218507 and OCE-9820172 to J.H.C.

\section{LITERATURE CITED}

Arkett SA (1984) Diel vertical migration and feeding behavior of a demersal hydromedusan (Polyorchis penicillatus). Can J Fish Aquat Sci 41:1837-1843

Colin SP, Costello JH (1996) Relationship between morphology and hydrodynamics during swimming by the hydromedusae Aequorea victoria and Aglantha digitale. Sci Mar 60:35-42

Colin SP, Costello JH (2002) Morphology, swimming perfor- 
mance and propulsive mode of six co-occurring hydromedusae. J Exp Biol 205:427-437

Costello JH (1992) Foraging mode and energetics of hydrozoan medusae. Sci Mar 56:185-191

Costello JH, Colin SP (1994) Morphology, fluid motion and predation by the scyphomedusae Aurelia aurita. Mar Biol 121:327-334

Costello JH, Colin SP (1995) Flow and feeding by swimming scyphomedusae. Mar Biol 124:399-406

Costello JH, Colin SP (2002) Prey resource use by coexistent hydromedusae from Friday Harbor, Washington. Limnol Oceanogr 47:934-942

Costello JH, Klos E, Ford MD (1998) In situ time budgets of the scyphomedusae Aurelia aurita, Cyanea sp., and Chrysaora quinquecirrha. J Plankton Res 20:383-391

Daniel TL (1983) Mechanics and energetics of medusan jet propulsion. Can J Zool 61:1406-1420

Daniel TL (1985) Cost of locomotion: unsteady medusan swimming. J Exp Biol 119:149-164

Ford MD, Costello JH, Klos E (1997) Swimming and feeding by the scyphomedusa Chrysaora quinquecirrha. Mar Biol 129:355-362

Gladfelter WG (1973) A comparative analysis of the locomotory systems of medusoid Cnidaria. Helgol Wiss Meeresunters 25:228-272

Larson RJ (1987) Trophic ecology of planktonic gelatinous predators in Saanich Inlet, British Columbia: diets and prey selection. J Plankton Res 9:811-820

Editorial responsibility: Thomas Kiørboe (Contributing Editor), Charlottenlund, Denmark
Leonard JL (1980) Temporal organization of swimming activity in Sarsia tubulosa M. Sars (Hydrozoa). J Comp Physiol 136:219-225

Mackie GO, Larson RJ, Larson KS, Passano LM (1981) Swimming and vertical migration of Aurelia aurita (L.) in a deep tank. Mar Behav Physiol 7:321-329

Madin LP (1988) Feeding behavior of tentaculate predators: in situ observations and a conceptual model. Bull Mar Sci 43:413-429

Matsakis S, Conover RJ (1991) Abundance and feeding of medusae and their potential impact as predators on other zooplankton in Bedford Basin (Nova Scotia, Canada) during spring. Can J Fish Aquat Sci 48:1419-1430

Mills CE (1981) Diversity of swimming behaviors in hydromedusae as related to feeding and utilization of space. Mar Biol 64:185-189

Mills CE (1983) Vertical migration and diel activity patterns of hydromedusae: studies in a large tank. J Plankton Res 5: 19-35

Purcell JE, Grover JJ (1990) Predation and food limitation as causes of mortality in larval herring at a spawning ground in British Columbia. Mar Ecol Prog Ser 59:55-61

Purcell JE, Mills CE (1988) The correlation between nematocyst types and diets in pelagic hydrozoa. In: Hessinger DA, Lenhoff HM (eds) The biology of nematocysts. Academic Press, San Diego, CA, p 463-485

Siegel S, Castellan NJ (1988) Nonparametric statistics for the behavioral sciences, 2nd edn. McGraw-Hill, New York

Submitted: November 11, 2002; Accepted: February 18, 2003 Proofs received from author(s): May 2, 2003 